\title{
Clearing the Haze: Navigating Corneal Refractive Surgery in Patients with Posterior Polymorphous Corneal Dystrophy
}

\author{
Majid Moshirfar (D) - Alyson N. Tukan · Nour Bundogji
}

Received: May 28, 2021 / Accepted: June 10, 2021 / Published online: June 24, 2021

(C) The Author(s) 2021

\begin{abstract}
Posterior polymorphous corneal dystrophy (PPCD) is a corneal disorder of the endothelium and Descemet's membrane. Although reports of corneal refractive surgery including laser-assisted in situ keratomileusis (LASIK), photorefractive keratectomy (PRK), and small incision lenticule extraction (SMILE) in PPCD are minimal, these procedures have been shown to be safe and effective in this patient population. Proceeding with corneal refractive surgery in eyes with PPCD raises concerns regarding corneal integrity, including long-term biomechanical instability, risk of ectasia, endothelial
\end{abstract}

cell loss, disease progression, and corneal decompensation. Thus, LASIK, PRK, and SMILE should be considered with caution. This commentary explores the patient characteristics associated with favorable surgical outcomes and factors that weigh against proceeding with refractive surgery.

Keywords: Ectasia; Endothelial cell density; LASIK; PPCD; PPMD; PRK; Refractive surgery; SMILE

M. Moshirfar ( $\square)$

Hoopes Vision Research Center, Hoopes Vision, 11820 S. State St., Ste.200, Draper, UT 84020, USA e-mail: cornea2020@me.com

M. Moshirfar

John A. Moran Eye Center, University of Utah

School of Medicine, Salt Lake City, UT, USA

M. Moshirfar

Utah Lions Eye Bank, Murray, UT, USA

A. N. Tukan · N. Bundogji

University of Arizona College of Medicine Phoenix,

Phoenix, AZ, USA 


\section{Key Summary Points}

Posterior polymorphous corneal dystrophy is a posterior dystrophy involving the epithelium and Descemet's membrane, causing blurred vision, halos, corneal edema, vesicles, and band-like lesions.

Minimal studies on corneal refractive surgery in this patient population have been reported, though surgery has been shown to be safe and effective in patients with mild disease sparing the central visual axis.

Considerations for proceeding with refractive surgery include preoperative topography, endothelial cell density (ECD), corneal thickness, and disease morphology.

A thorough preoperative discussion with patients pursuing corneal refractive surgery should include the potential for disease progression, risk of unpredictable visual outcomes, refractive regression, further ECD loss, corneal decompensation, and postoperative keratoconus/ectasia.

\section{DIGITAL FEATURES}

This article is published with digital features, including a summary slide, to facilitate understanding of the article. To view digital features for this article go to https://doi.org/10.6084/ m9.figshare.14763312.

Posterior polymorphous corneal dystrophy (PPCD), also known as posterior polymorphous dystrophy (PPMD), is a corneal disorder of the endothelium and Descemet's membrane. It is categorized as a posterior dystrophy, alongside Fuchs dystrophy and congenital endothelial dystrophy [1]. Although corneal dystrophies are usually bilateral, PPCD may present unilaterally with asymmetric symptoms [2, 3]. Some patients with PPCD are asymptomatic [1], while others can present with blurred vision, halos, and corneal edema [4] ranging from minimal edema to bullous keratopathy [3]. Other findings include thickening of Descemet's membrane with anterior chamber excrescences [1]; scalloped, refractile band-like lesions [1, 3]; posterior corneal vesicles surrounded by gray haze $[1,3]$; iris angle adhesions $[1,3,4]$; and epithelialization of the endothelium $[1,5]$. The endothelial cell density (ECD), especially in vesicular and diffuse morphologies, is typically lower than that of a healthy eye but does not decrease at a faster rate over time than what is observed in normal aging [6]. As a result of concerns regarding the corneal integrity in PPCD, the question emerges whether it is safe to perform elective corneal laser vision correction surgeries, such as laser in situ keratomileusis (LASIK), photorefractive keratectomy (PRK), or small incision lenticule extraction (SMILE). The present article explores the ramifications and precautions for proceeding with laser vision correction and provides guidelines for performing corneal refractive surgery in this patient population.

To begin the discussion, it is important to understand corneal histological changes after laser refractive surgery. In healthy eyes, acute inflammatory reaction in the immediate postoperative period is observed after LASIK [7] and PRK [8]. On specular microscopy, corneal swelling and distortion of normal hexagonal endothelial cells are noted, though these changes do not persist over time $[9,10]$. There is controversy whether the ECD is stable [10] or decreased [11] on long-term follow-up, but any changes observed in ECD do not appear to cause visual impairment [11]. Loss of stromal barrier function has also been noted after refractive surgery with deposition of granular material in Descemet's membrane, especially in patients undergoing ablation for high myopia [12]. Despite these findings in the setting of corneal refractive surgery, there seem to be no longterm visual consequences in healthy eyes.

Refractive surgery in eyes with corneal dystrophy has been debated, and there are few reports of laser vision correction in PPCD. To 
date, eyes with PPCD have had more favorable outcomes after LASIK than other corneal dystrophies [13]. Both PRK and LASIK have been found to be safe for patients with mild disease [14]. Specifically, two patients with vesicular PPCD experienced visual outcomes within the expected range for healthy eyes after LASIK, despite a decrease in ECD of $2.3 \%$ at 1 year postoperatively [15]. Cohorts of patients with vesicular or band-like morphology achieved postoperative vision of $20 / 20$ or better $[16,17]$. Patients with ECD $>2000$ cells $/ \mathrm{mm}^{2}$ had no significant decrease in ECD postoperatively after PRK [17]. Interestingly, Isager et al. state that a low preoperative ECD is associated with greater postoperative loss [11], suggesting that patients with high preoperative ECD are better surgical candidates. Similar outcomes have been reported after SMILE, with one patient achieving uncorrected visual acuity of 20/20 bilaterally without evidence of disease progression 12 months postoperatively [18]. These cases are encouraging for patients with PPCD seeking corneal refractive surgery, as they illustrate that careful preoperative selection criteria can yield good visual outcomes for patients who are deemed appropriate candidates.

Although the sample size of patients with PPCD who have undergone PRK, LASIK, and
SMILE is small, we still conclude that corneal refractive surgery can be safe and effective. Table 1 summarizes the patient characteristics associated with favorable surgical outcomes and factors that recommend against proceeding with refractive surgery. Notably, patients with mild vesicular and band morphology sparing the central three to $5 \mathrm{~mm}$ of the visual axis are safer surgical candidates. Central lesions limit the postoperative visual potential, and patients should be advised accordingly. Healthier preoperative ECD also bodes well for good surgical outcomes. On the other hand, surgery should generally be avoided in patients with diffuse disease, where a corneal transplant may eventually be indicated [14].

Corneal topography plays a substantial role in preoperative counseling for refractive surgery in healthy eyes, and it should be weighted equally, if not more, heavily for patients with PPCD. Aldave et al. noted an association between PPCD and keratoconus, which is thought to be due to a shared abnormality in the visual system homeobox 1 (VSX1) gene [19]. This gene association raises concern that patients with PPCD may be more predisposed to postoperative ectasia than the general population. It is not clear whether there is an association between corneal steepening and central

Table 1 Patient characteristics associated with favorable post-refractive outcomes and risk factors that weigh against proceeding with refractive surgery in patients with PPMD

\begin{tabular}{ll}
\hline Protective factors & Risk factors \\
\hline $\begin{array}{l}\text { Minimal to mild visual symptoms } \\
\begin{array}{l}\text { Vesicular and band morphology sparing the central } \\
\text { visual axis }\end{array}\end{array}$ & $\begin{array}{l}\text { Severe visual impairment } \\
\text { Diffuse morphology, lesions affecting the central visual axis }\end{array}$ \\
Normal corneal topography & $\begin{array}{l}\text { Topography with steep corneas concerning for pre-existing } \\
\text { keratoconus }\end{array}$ \\
Open angles, healthy optic nerves & Narrow angles, glaucomatous nerve changes \\
Thick CCT & Thin CCT \\
ECD $\geq 2000$ cells $/ \mathrm{mm}^{2}$ & ECD $<2000$ cells $/ \mathrm{mm}^{2}$ \\
Healthy hexagonal morphology & Pleomorphic endothelial cells
\end{tabular}

$C C T$ central corneal thickness, ECD endothelial cell density 
corneal thickness [19]; thus further observations are needed. We recommend that surgeons exercise a low threshold for advising against corneal refractive surgery in patients with suspicious or markedly steep keratometry.

A discussion of corneal refractive surgery in patients with PPCD would not be complete without diving into the anterior and posterior segments of the eye. Glaucomatous cupping induced by iris angle adhesions decreases visual potential, irrespective of refractive corrections. Thorough gonioscopy and dilated fundoscopic exam are warranted in the preoperative evaluation to ensure that patients with PPCD seeking PRK, LASIK, or SMILE have open angles and healthy optic nerves. Furthermore, the extensive postoperative steroid regimen, especially in PRK, places patients who are already predisposed to glaucoma at high risk for nerve damage.

Some have questioned whether preoperative gene testing is indicated for PPCD. As a result of the autosomal dominant inheritance pattern, eliciting a family history can help identify patients who may have asymptomatic PPCD. Different gene mutations stratify the three types of PPCD (type 1, unknown; type 2, COL8A2 gene on chromosome $1 \mathrm{p} 34.3$; type 3 , TCF 8 gene on chromosome 10p11.22) [1], along with abnormalities in the ZEB1 gene on chromosome 10p11.2 [20]. The lack of certainty about gene associations, as well as overlap between genetic abnormalities in PPCD, keratoconus, and other corneal dystrophies argues against the implementation of routine genetic screening at this time.

In conclusion, data on visual outcomes after LASIK, PRK, and SMILE in patients with PPCD is minimal. However, corneal refractive surgeries have been performed with successful outcomes in patients with mild disease, healthy preoperative ECD, and regular topography. Some caveats for surgeons to consider during preoperative counseling include the risk of unpredictable visual outcomes, refractive regression, further ECD loss, corneal decompensation, and postoperative keratoconus/ectasia. Patients should be aware that disease progression is possible in the setting of corneal refractive surgery, which may limit the success of their refractive outcomes. If proceeding with laser vision correction, it is imperative for the surgeon and patient to have a detailed discussion about these potential outcomes.

\section{ACKNOWLEDGMENTS}

Funding. This study was funded by an unrestricted grant from Research to Prevent Blindness (RPB), 360 Lexington Avenue, 22nd Floor New York, NY 10017, USA. No support was received for the publication of this article.

Medical Writing/Editorial Assistance. Special thanks to Shannon McCabe and Yasmyne Ronquillo for their assistance in editing.

Authorship. All named authors meet the International Committee of Medical Journal Editors (ICMJE) criteria for authorship for this manuscript, take responsibility for the integrity of the work, and have given final approval to the version to be published.

Authorship Contributions. Majid Moshirfar MD contributed to the perspective conception. The first draft of the manuscript was written by Alyson Tukan and Nour Bundogji. All authors contributed to revisions.

Disclosures. All authors declare that they have no conflict of interest.

Compliance with Ethics Guidelines. This article is based on previously conducted studies and does not contain any studies with human participants or animals performed by any of the authors.

Data availability. Data sharing is not applicable to this article as no datasets were generated or analyzed during the current study.

Publication Originality Statement. We confirm that this publication is original.

Open Access. This article is distributed under the terms of the Creative Commons 
Attribution-Non Commercial 4.0 International License (http://creativecommons.org/licenses/ by-nc/4.0/), which permits any noncommercial use, distribution, and reproduction in any medium, provided you give appropriate credit to the original author(s) and the source, provide a link to the Creative Commons license, and indicate if changes were made.

\section{REFERENCES}

1. Klintworth GK. Corneal dystrophies. Orphanet J Rare Dis. 2009. https://doi.org/10.1186/1750-11724-7.

2. Weiss JS, Møller HU, Aldave AJ, et al. IC3D classification of corneal dystrophies-edition 2. Cornea. 2015;34(2):117-59. https://doi.org/10.1097/ICO. 0000000000000307.

3. Krachmer JH. Posterior polymorphous corneal dystrophy: a disease characterized by epithelial-like endothelial cells which influence management and prognosis. Trans Am Ophthalmol Soc. 1985;83: 413-75.

4. Moshirfar M, Bennett P, Ronquillo Y. Corneal Dystrophy. In: StatPearls. Treasure Island (FL): StatPearls Publishing; January 21, 2021.

5. Frausto RF, Chung DD, Boere PM, et al. ZEB1 insufficiency causes corneal endothelial cell state transition and altered cellular processing. PLoS ONE. 2019;14(6):e0218279. https://doi.org/10. 1371/journal.pone.0218279.

6. Fung SSM, Sami H, El Hamouly A, et al. Endothelial cell density in children with posterior polymorphous corneal dystrophy: a longitudinal case-control study. Eye. 2021. https://doi.org/10.1038/ s41433-021-01451-y.

7. Kim JS, Chung B, Lee T, Kim WC, Kim TI, Kim EK. Management of long-standing partially torn and flipped laser in situ keratomileusis flaps. J Cataract Refract Surg. 2015;41(2):464-7. https://doi.org/10. 1016/j.jcrs.2014.11.033.

8. Carones F, Brancato R, Venturi E, Morico A. The corneal endothelium after myopic excimer laser photorefractive keratectomy. Arch Ophthalmol. 1994;112(7):920-4. archopht.1994.01090190068023.

9. Carones F, Brancato R, Venturi E, Vigo L. The human corneal endothelium after myopic excimer laser photorefractive keratectomy immediate to one-month follow-up. Eur J Ophthalmol. 1995;5(4): 204-13.

10. Mardelli PG, Piebenga LW, Matta CS, Hyde LL, Gira J. Corneal endothelial status 12 to 55 months after excimer laser photorefractive keratectomy. Ophthalmology. 1995;102(4):544-9. https://doi.org/10. 1016/S0161-6420(95)30984-0.

11. Isager P, Guo S, Hjortdal J, Ehlers N. Endothelial cell loss after photorefractive keratectomy for myopia. Acta Ophthalmol Scand. 1998;76(3):304-7. https:// doi.org/10.1034/j.1600-0420.1998.760310.x.

12. Edelhauser HF. The resiliency of the corneal endothelium to refractive and intraocular surgery. Cornea 2000;19:263-73.

13. Rocha-de-Lossada C, Rachwani-Anil R, ColmeneroReina E, Borroni D, Sánchez-González J-M. Laser refractive surgery in corneal dystrophies. J Cataract Refract Surg. 2021;47(5):662-70. https://doi.org/10. $1097 /$ j.jcrs.0000000000000468.

14. Woreta FA, Davis GW, Bower KS. LASIK and surface ablation in corneal dystrophies. Surv Ophthalmol. 2015;60(2):115-22. https://doi.org/10.1016/j. survophthal.2014.08.003.

15. Moshirfar M, Barsam CA, Tanner MC. Laser in situ keratomileusis in patients with posterior polymorphous dystrophy. Cornea. 2005;24(2):230-2. https:// doi.org/10.1097/01.ico.0000139634.88153.bb.

16. Abdelwahab S, Elfayoumi M. LASIK in selected patients with posterior polymorphous corneal dystrophy. J Egypt Ophthalmol Soc. 2016;109:60-4. https://doi.org/10.4103/2090-0686.193402.

17. Bower KS, Trudo EW, Ryan DS, et al. Photorefractive keratectomy in posterior polymorphous dystrophy with vesicular and band subtypes. J Cataract Refract Surg. 2011;37(6):1101-8. https://doi.org/10. 1016/j.jcrs.2010.12.045.

18. Park JH, Lee JH, Koo HJ. Small-incision lenticule extraction in posterior polymorphic corneal dystrophy. J Cataract Refract Surg. 2016;42(5):795-7. https://doi.org/10.1016/j.jcrs.2016.04.001.

19. Aldave AJ, Ann LB, Frausto RF, Nguyen CK, Yu F, Raber IM. Classification of posterior polymorphous corneal dystrophy as a corneal ectatic disorder following confirmation of associated significant corneal steepening. JAMA Ophthalmol. 2013;131(12): 1583-90. https://doi.org/10.1001/jamaophthalmol. 2013.5036.

20. Zhang Y, Liu X, Liang W, Dean DC, Zhang L, Liu Y. Expression and function of ZEB1 in the cornea. Cells. 2021;10(4):925. https://doi.org/10.3390/ cells10040925. 